\title{
PROBLEMS OF COTTON SEED STOCK PRODUCING IN THE VARIETIES OF GOSSYPIUM HIRSUTUM
}

\author{
Khamidulla Sheraliev \\ Candidate of Agricultural Sciences, Professor of the Department of Farming and Melioration, \\ Tashkent State Agrarian University, University str., 3, Tashkent-100140, Uzbekistan. \\ Mardon Nurbaevich Aberkulov \\ Associate professor, Department of Genetics, Plant Breeding and Seed Production of Agricultural Crops, Tashkent State Agrarian \\ University, University str., 3, Tashkent-100140, Uzbekistan.

\section{Murod Said-Akbarovich Rakhmankulov} \\ Professor, Head of the Department of Genetics, Plant Breeding and Seed Production of Agricultural Crops, Tashkent State Agrarian \\ University, University str., 3, Tashkent-100140, Uzbekistan. \\ Muso Eshmurodovich Ashurov \\ Senior Teacher, Department of Genetics, Plant Breeding and Seed Production of Agricultural Crops, Tashkent State Agrarian \\ University, University str., 3, Tashkent-100140, Uzbekistan. \\ Mamur Musakhanovich Jumashev \\ Senior Teacher, Department of Genetics, Plant Breeding and Seed Production of Agricultural Crops, Tashkent State Agrarian \\ University, University str., 3, Tashkent-100140, Uzbekistan.

\section{Rasulov Ilkhom Makhmudovich} \\ Associate professor, Department of Genetics, Plant Breeding and Seed Production of Agricultural Crops, Tashkent State Agrarian \\ University, University str., 3, Tashkent-100140, Uzbekistan.
}

\section{Tilovova Gavkhar Abdakhatovna}

Senior Teacher, Department of Languages,

Tashkent State Agrarian University, University str., 3, Tashkent-100140, Uzbekistan.

DOI: https://doi.org/10.36713/epra3814

\section{ABSTRACT}

Radically enhancing of employed technologies on the growing of agricultural crops in Uzbekistan and quality of varieties has become one of the major challenges in the state priority today. Because, in the example of cotton plant as the principle crop, the republic is remaining far behind on cotton raw productivity $-12^{\text {th }}$, and on cotton fiber productivity-29th than cotton producing countries. At this term, the state is a head reformer extending all scientific-technical and organizing measurements for the development of this field.

The results on the study of seed stock cotton varieties' cultivation for two years $(2018,2019)$ in the Burkhon farm, Navoiy division of Oqqorgon district, Tashkent region were presented in this paper. Planting quality, influences of seeds on the seed sprouting period, field germination of seed stocks, optimal seed stock expenditure, optimal seedling density, plants' development and dynamics of yield components setting were studied in the field observations.

It was identified that the used drill has planted at minimum, from 9 and maximum, up to 29 seeds per $1 \mathrm{~m}$ of a row. Coefficient of variation, according to the outcome of statistical analysis on the determination of difference between these two indexes has made of $29.7 \%$.

Field germination, height of plants, instability on the plants' boll numbers and share of contamination in the variety traits of varieties were also analyzed and the necessary recommendations on new innovative ideas and technologies for improving of cotton seed production in grooving varieties and producing of seed stocks were given.

KEYWORDS: Cotton, seed, germination, seed stock, technology, sprouts, variety, Sultan, S-6524. 


\section{INTRODUCTION}

The farmers in cotton growing of Uzbekistan face on the great problems at the period of cotton seed planting to get healthy sprouts. Variation of spring weather $[2,5]$ and imperfection of planting techniques [4] are the causes of this. Consequently, in the place of 22-25 kgs of seed stock [11] which provide to get yield of 2,5-3.1 tons $\backslash$ ha, it requires up to $80 \mathrm{~kg}$ seed stock to spend [9].

In particular, the resolution [1] of the president of the Republic of Uzbekistan "About the additional measurements on the perfection of mechanisms of economical fields and introduction of innovations in the fields" covers mapping of measures to comprehensively encouraging innovational development and innovatory ideas for dealing with above mentioned problems.

A numerous researches and inventions have been implemented and efficient recommendations extended into production for perfection of planting, optimization of expanding seed amount, to protect seedlings from the effects of diseases and pests and to decrease exceeded expenditures.

In particular, existence of technology facilitating economy of seed stock up to 30 kilograms from usually expending per hectare had been studied and the outcome was advertised as the recommendation [3]. But that technology was sooner rejected by the farmer sowing to application of oil paper and other organizational works involved in seed sowing which lead to increase extra expenditures.

Today, the most of seed drills employing in the cotton growing of Uzbekistan consist of partially improved to date modifications from old drills [4, 20]. Among them there are seeders with opportunities near hill-drop, furrow, square-hill drop, hill-drop and precision unit sowing.

In the analysis of practices of the word countries $[14,15]$ with advanced cotton growing it was clear that the productivity and product quality of newly developed varieties mostly dependent on their cultivation technologies. But here, variety's efficacy determines by the stability of productivity related on the heritable uniformity of the variety [21]. Accordingly, recommendations [11] of our breeders on the optimal agro-practices to use more efficiently from the full heritable potentiality of the varieties are either extended to the farmers. Unfortunately, our republic is remaining behind at rank on 12 places the raw cotton producing and at the rank on 29 places in the cotton fiber yield within cotton producing countries' list [17, 18 and 19]. Here, like to other developed countries the availability rate of seed planting technology which possible to get optimal number of seedlings in short time has a first and major significance in our cotton growing. Because, according to scientists counting, $[6,7,9,12]$ beginning of seed sprouting in 30 days, 80 percent of cotton crop is created in whole growing and vegetation period.

We, in our experiments (in 2018 and 2019) have studied planting quality, influence of cotton seeds number on the germination period, field germination of cotton seed stock, optimal cotton seed expend, optimal plant density, development of plants and setting dynamics of yield components.

\section{MATERIALS AND METHODS}

The experiment has been implemented in the farm Burkhan, A.Navoiy division, Okkurgan district, Tashkent region. The farm is one of the example farms, sufficiently provided with technique which has specified to produce cotton seed stock. Farm has totally 47 hectares of field. F1 plants of the variety S-6524 in 2018 and F1 plants of the variety Sultan in 2019 were grown to reproduce their seed stocks. The seeds dried, atrichous and hairless were treated with chemical.

Seed sowing in 2018 has been carried out on the

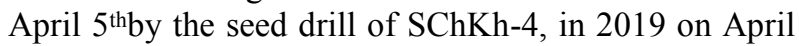
$3-4^{\text {th }}$ by the seed drill of Rumin (foreign modification). Rows are $0.9 \mathrm{~m}$. Seed planting rate has not been concretely adjusted. It was adjusted on average seed expending rate on the base of multiyear experiences.

10 special samples which has $1 \mathrm{~m}$ row long, remarked with wooden pegs on the diagonal of the field rows have been separated after general planting. The numbers of stuck seeds in the soil per every sample and studied with careful opening way of the soil and seed. The color of chemical which had been used to treat seeds basically helped us to discover easily the stuck seeds and enhanced the monitoring precision. The taken data were recorded in the field register. Samples, the seeds were rapidly covered again back on their places in proper soil compact. The real opportunity of seeder was defined by the means of determined seed number and order of seeds. Indexes of mean differences on the experimental field have been analyzed by the statistical method [16] accepted for data analysis of agricultural crops.

Field germination, number of plants per sample area, plant stand order, development and yield of plants have been studied during the vegetation. The number of plants per hectare is calculated by the expanding of the $1 \mathrm{~m}$ sample area up to $11.1 \mathrm{~m}$ and the taken data successively transformed into hectare. And the accumulating of yield components has been identified through the calculation of the number of bolls on the 10 sample plants picked out the simples of varieties at the certain period of the year. Variety uniformity also was methodically [8] examined by the approbation in the case of exceeding differences of data than requirement of statistical variation levels.

\section{RESULTS AND DISCUSSION}

The seed planters employed in the farm is common one for all cotton growing farms in the industry.

Data collected from $1 \mathrm{~m}$ long samples of rows laid through field diagonal illustrated in the table 1. It was found that the numbers of planted seeds along the $1 \mathrm{~m}$ samples were not even. According to the data of the table, the minimum and maximum numbers in the samples are correspondingly range from 9 to 29 . In the result of statistical analysis it was established that the differences of these indexes made of $29.7 \%$ of variation coefficient. In the terms of row length in the samples 
and row length in one hectare, this outcome shows that the drill's operation in the field of farm is considerable

inefficient.

Table 1

The number of seeds stuck in $1 \mathrm{~m}$ row length by the seeder and field germination of seed stock (2018)

\begin{tabular}{|c|c|c|c|c|c|c|c|c|}
\hline \multirow{2}{*}{$\begin{array}{c}\text { № of } \\
\text { samples }\end{array}$} & \multirow{2}{*}{$\begin{array}{l}\text { Number of } \\
\text { planted } \\
\text { seeds, units }\end{array}$} & \multirow{2}{*}{$\begin{array}{l}\text { Date of } \\
\text { planting }\end{array}$} & \multicolumn{5}{|c|}{$\begin{array}{l}\text { Emerging of seedlings, date of inspection } \\
\text { and in units }\end{array}$} & \multirow{2}{*}{$\begin{array}{c}\text { Seedlings, } \\
\text { relatively to } \\
\text { the number of } \\
\text { planted, in \%. }\end{array}$} \\
\hline & & & 17.04 & 20.04 & 24.04 & 27.04 & 30.04 & \\
\hline 1 & 18 & 5.04 .2018 & - & - & 6 & 9 & 11 & 61.1 \\
\hline 2 & 20 & $-\backslash \backslash-$ & - & 6 & 11 & 12 & 13 & 65.0 \\
\hline 3 & 20 & $-\backslash \backslash-$ & 2 & 3 & 18 & 19 & 20 & 100 \\
\hline 4 & 14 & $-11-$ & 1 & 1 & 6 & 8 & 10 & 71.4 \\
\hline 5 & 29 & $-\backslash 1-$ & - & - & 15 & 20 & 26 & 89.6 \\
\hline 6 & 9 & $-\backslash 1-$ & - & 1 & 4 & 8 & 9 & 100 \\
\hline 7 & 20 & $-\backslash \backslash-$ & - & 1 & 12 & 14 & 16 & 80.0 \\
\hline 8 & 21 & $-\backslash \backslash-$ & - & 1 & 11 & 15 & 18 & 85.7 \\
\hline 9 & 13 & $-\backslash \backslash-$ & - & - & 7 & 10 & 12 & 92,3 \\
\hline 10 & 18 & $-\backslash \backslash-$ & - & - & 9 & 10 & 12 & 66,6 \\
\hline $\begin{array}{c}\text { Total } \\
\text { Mean and } \\
\text { its error } \\
\text { Coefficient } \\
\text { variation }\end{array}$ & $\begin{array}{c}182 \\
18,2 \pm 1.7 \\
29.7 \%\end{array}$ & & 3 & 13 & 99 & 125 & $\begin{array}{c}149 \\
\text { or } \\
81,9 \% \\
25 \%\end{array}$ & Mean: 81,2 \\
\hline
\end{tabular}

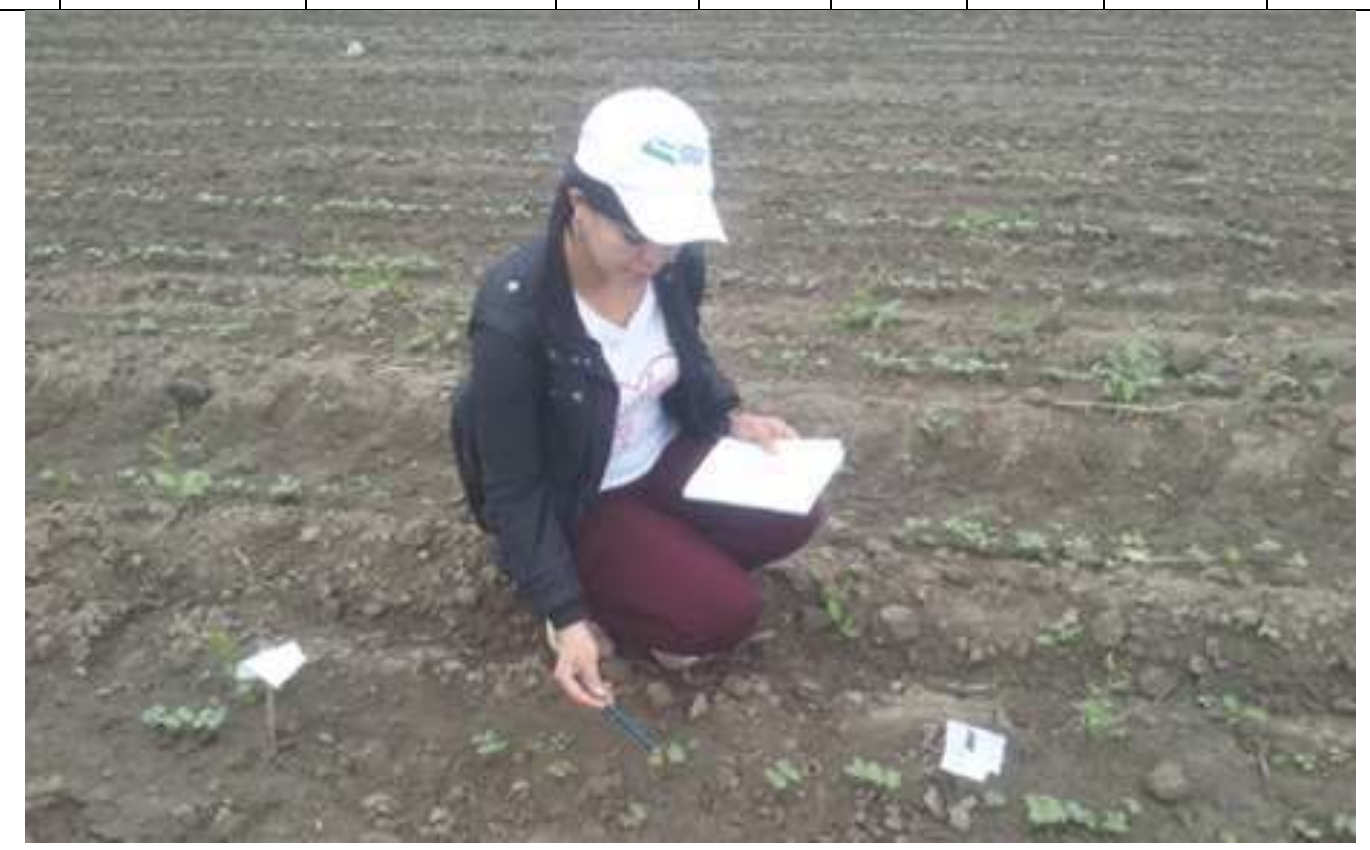

Figure 1. Researcher L.Safaralieva is inspecting the field germination of seed stocks in the sample.

Field germination of planted seeds which had been sown in the natural moisture of spring in 2018 was observed from $17^{\text {th }}$ to $30^{\text {th }}$ of May (Figure 1).

Field germination has revealed the indexes ranging from 61 to 100 per cents. The mean germination on the samples made of $81.2 \%$ (table 1). There was not remarked one side relation between number of seeds and germination. For example, if the sample with 20 seeds shows $100 \%$ of germination ( $3^{\text {rd }}$ sample), meanwhile the sample (6 $6^{\text {th }}$ sample) with 9 seeds also shows a $100 \%$ germination. Contrarily, samples with many seeds (20 seeds in the sample 2 and 18 seeds in the sample 10) have lagged far lower, at the per cents of 65 and 67. In the other samples either were not notable relation between these two indexes. The samples of 6 (with 9 seeds) and 9 (with 13 planted seeds) having 100 and $92 \%$ of seed germination indexes attracted the attentions of the researchers. It means that, there is an opportunity to attaining the best germination by the planting 9, 10 seeds per one meter for the seed saving of the variety of S-6524. 
Effect of seed number in the row sample on the period length of germination has also been analyzed. In this, the very short period which was 3 days was established only in the sample with 29 seeds. This confirms the conclusions about the high germinations due to many seeds stuck per a nest by the majority of scientists.

But, in our experiments, 4 and 5 days durability has been observed in both of 20 or 9 seeds per nest sowing depending on the possibilities of employed seeder and here in after, above mentioned inference is characteristic to the situations when 29 and more seeds were planted per 1 meter.

Planting of different numbers of seeds per 1 meter row likely to previous year was monitored in 2019 in spite of planting implemented by other seeder (table 2). The differences in the seed numbers (from 9 to 29) are almost similar to previous year (from 9 to 27).

The period of field germination in 2019 has begun since the $6^{\text {th }}$ day ( $7^{\text {th }}$ day in the previous year) after planting and implemented for 18 days (20 days in the previous year).

Field germination of seed stocks in 2019 has made of 53.8 to $100 \%$ per samples. These indexes in 2018 were 61 to $100 \%$ and the yearly difference has made of $7.2 \%$. This difference was associated with temperature and moisture of the years [5] or variety differences. If this was associated with varieties, the seeds of the variety S-6524 have showed slightly higher field germination than seeds of variety Sultan.

The lowest seed germination of the variety of Sultan is exhibited by the $75.7 \%$ mean germination, pronounced in percent than numbers of planted seeds according to the seedlings of the table 2 .

The situation of 2018 was continued when we analyzed the relation between number of seeds and germination. The high germinations(with the number 24 and 27) in the samples were observed in the $1^{\text {st }}$ and $2^{\text {nd }}$ samples or 79.2 and $100 \%$ correspondingly. The least numbers (7 and 9) which were in the samples 3 and 6 showed 85.7 and $100 \%$ germinations. The difference between them was $6.5 \%$ more and 7, 9 seeds were planted per 1 meter on the variety Sultan. This illustrates that planting of 7 to 9 seeds per every 1 meter is the best opportunity on the variety Sultan.

Germination period of seed stock per 1 meter showed the situation of 2018 , in which the majority of seeds germinated within 4 and 5 days. At this largeness or less of seeds in some of samples does not reflect any similar differences. Germination days do not decreased by the increasing of seed numbers (in the samples of 1 , 2 and 10).

Table 2

Numbers of seeds planted in $1 \mathrm{~m}$ of row by drill and field germination in 2019

\begin{tabular}{|c|c|c|c|c|c|c|c|c|}
\hline \multirow[b]{2}{*}{ Samples } & \multirow[b]{2}{*}{$\begin{array}{l}\text { Number of } \\
\text { planted } \\
\text { seeds, unit }\end{array}$} & \multirow[b]{2}{*}{$\begin{array}{c}\text { Date of } \\
\text { planting }\end{array}$} & \multicolumn{6}{|c|}{ Emerging of sprouts and lost } \\
\hline & & & 10.04 & 13.04 & 16.04 & 19.04 & 22.04 & $\begin{array}{c}\text { Sprouts, relatively } \\
\text { to number of } \\
\text { planted seeds, } \% .\end{array}$ \\
\hline 1 & 24 & $\begin{array}{c}04.04 . \\
2019\end{array}$ & 4 & 6 & 10 & 14 & 19 & 79.2 \\
\hline 2 & 27 & $-\backslash \backslash-$ & 6 & 10 & 16 & 22 & 27 & 100 \\
\hline 3 & 7 & $-\backslash \backslash-$ & - & 2 & 3 & 5 & 6 & 85.7 \\
\hline 4 & 17 & $-\backslash \backslash-$ & 1 & 3 & 8 & 12 & 15 & 88.2 \\
\hline 5 & 17 & $-\backslash \backslash-$ & - & 2 & 7 & 11 & 15 & 88.2 \\
\hline 6 & 9 & $-\backslash \backslash-$ & - & 1 & 3 & 7 & 9 & 100 \\
\hline 7 & 16 & $-\backslash \backslash-$ & 2 & 5 & 9 & 13 & 16 & 100 \\
\hline 8 & 14 & $-\backslash \backslash-$ & - & 3 & 6 & 8 & 10 & 71.4 \\
\hline 9 & 13 & $-11-$ & - & 1 & 4 & 5 & 7 & 53.8 \\
\hline 10 & 23 & $-\backslash \backslash-$ & 3 & 6 & 10 & 15 & 18 & 78.3 \\
\hline $\begin{array}{c}\text { Mean: } \\
\text { Coefficient } \\
\text { of variation }\end{array}$ & $\begin{array}{c}16.7 \\
31.5 \%\end{array}$ & & & & & & $\begin{array}{c}14.2 . \\
28.9 \%\end{array}$ & $\begin{array}{c}75.7 . \\
34.0 \%\end{array}$ \\
\hline
\end{tabular}

According to the above tables (1 and 2) the plants out of exceeded seeds than determined optimal numbers $(9,10$ seeds per 1 meter in 2018; 7, 9 seeds in 2019) create unnecessary density amongst plants. Naturally, as the conditions of agricultural industry, exceeded plants caused of extra job necessity involved in thinning of crowded out plants through the extermination of exceeded plants by hand of peasants.
Thinning is implemented by temporarily hired local workers (Figure 2).

Report about the thinning, its orders, how to do it in a proper way was reached to the workers by the farmer.

Information about sprouts and thinning taken in 2018 illustrated in the table 3 . According to the data of this table it is obvious that the number of sprouts recorded in the $1^{\text {st }}$ of May from the areas around the 
samples which are equal to one part $(11.1 \mathrm{~m})$ of hectare were calculated and presented. The numbers of sprouts prior to thinning were from103 (in the sample of 7) up to 232 units (in the sample of 3). The difference between these two samples made of 129 sprouts and no need result of any statistical analysis to show the importance of the difference. The greatness of the difference is explained by the lower actual work quality of the seeder. The average number of sprouts in the samples was equal to 177.1 units. The result of converting this data into one hectare makes of more than 177 thousand plants. Taking into account of the optimal number per hectare that would consists of 80-90 thousand, almost the half of above-mentioned sprouts must be exterminated by means of thinning. And this was done by the thinning. According to the data of table an average of 82 sprouts out of 117 were remained after thinning. The number of loosed sprouts made of 94.7 units an average. The percentage of exterminated sprouts in comparison with the number of sprouts prior to the thinning has established of $53.1 \%$. In the result of this index it is clear that more than a half of 16.3 to 37.1 kilograms [4] of seed stocks planting per hectare is lost in the thinning.

Thinning was not only extra expense and furthermore, its quality totally doesn't meet the requirement in terms of 80-90 thousand optimal plant stands. That is, the calculations after thinning (May 20) have exhibited that only 2 thinning (in 9 and 10) out of 10 sample thinning areas were properly fulfilled (table $3)$. Even, in sample areas of 2 and 6, where were opportunities to leave sufficient number of sprouts (prior to thinning there were 207 and 125 sprouts), after thinning are left 57 and 37 thousand per hectare in the reason of removing too more sprouts. In the result of this, some of the hectares of the field have 30000 to 50000 plants less than optimal number.

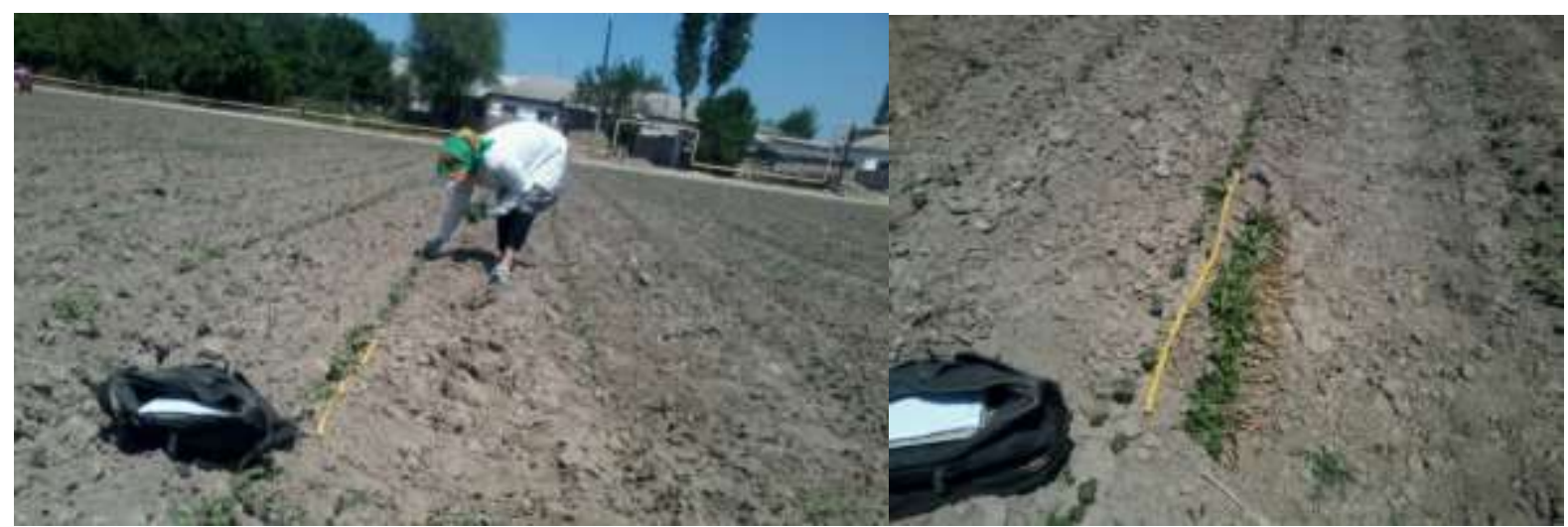

Figure 2. Thinning of sprouts to leave necessary plants in a certain area.

Table 3

Number of sprouts in the sample areas picked out of 10 points along the diagonal of the experimental plot (2018)

\begin{tabular}{|c|c|c|c|c|}
\hline $\begin{array}{c}\text { No of } \\
\text { samples, } \\
(\mathbf{1 1 . 1} \mathbf{M )} .\end{array}$ & $\begin{array}{c}\text { Number of sprouts } \\
\text { prior to thinning, } \\
\text { unit on May 1. }\end{array}$ & $\begin{array}{c}\text { Number of } \\
\text { sprouts after } \\
\text { thinning, unit on } \\
\text { May 20. }\end{array}$ & $\begin{array}{c}\text { Number of } \\
\text { removed sprouts, } \\
\text { unit. }\end{array}$ & $\begin{array}{c}\text { Ratio of number of } \\
\text { removed sprouts to the } \\
\text { number of sprouts } \\
\text { until thinning, in \%. }\end{array}$ \\
\hline 1. & 221 & 100 & 121 & 54,8 \\
\hline 2. & 207 & 57 & 150 & 72,5 \\
\hline 3. & 232 & 106 & 126 & 54,3 \\
\hline 4. & 143 & 60 & 83 & 58,0 \\
\hline 5. & 194 & 142 & 52 & 26,8 \\
\hline 6. & 125 & 37 & 88 & 30,4 \\
\hline 7. & 103 & 65 & 38 & 61,6 \\
\hline 8. & 185 & 71 & 114 & 52,5 \\
\hline 9. & 198 & 94 & 104 & 43,6 \\
\hline 10. & 163 & 92 & 71 & - \\
\hline Total: & 1771 & 824 & 947 & 53,1 \\
\hline Average: & 177,1 & 82,4 & 94,7 & \\
\hline
\end{tabular}

Dynamics of yield component setting and plant development in the experiment were performed at the states of above measurements and in the great differences of fulfilled measurements and plant developments (table 4).
The plants' height in the length of $11 \mathrm{~m}$ samples on $3^{\text {rd }}$ of June in 2018 consisted of $12.3 \mathrm{~cm}$. At this the very short plants occurred in the samples of 1,4 and 6 correspondingly: $6.5 ; 7.7$ and $7.5 \mathrm{~cm}$. The very height 
plants were recorded in the samples of 8,3 and 7 which have heights of $19.6 ; 18.6$ and 14.0 .

The number of plants in the samples on $20^{\text {th }}$ of May and height of plants on 3 rd of June were subjected to the analysis to identify existence of order or one side correlation between these two traits. It was obvious from the data of the table that one side development between number and height of plants was not remarked in 3 samples. One side correlated variation in the development of plants was recorded in the differences of numbers of retained from May 20 to September 23 plants in the areas of samples. At this time, if from 100 plants remain 82 plants in the $1^{\text {st }}$ sample, and from 57 plants remain 52 in the sample of 2. Again, from 106 plants in the $3^{\text {rd }}$ sample remain 87 . Similar variation occurred in the samples of 4 and 5, that is loose many plants from many number of plants and less from least number of plants. This order was observed in all other samples without $9^{\text {th }}$.
One side or positive correlation in two situations was noted in the analysis of plant numbers and an average accumulated boll numbers on 10 plants on $23^{\text {rd }}$ of September 2018. At the first, optimal numbers of plant stand were around: $82 ; 87$ and 82 in the samples of 1,3 and 5 , and boll numbers on the 10 plants consisted of $27 ; 39$ and 16 . At the second, plant stands in the samples 4, 6 and 8 were 57, 32 and 58, which accumulated 117, 74 and 69 boll numbers on the 10 plants correspondingly. That is naturally that decreasing of numbers in the plant stand per area causes of increasing the numbers of bolls. But, over the field an average plants' number made of 59.7, boll numbers were less -47.9 units. This shows that plants' numbers in the samples were not stable and so there are differences in the opportunities for accumulating yield components by the plants.

Table 4

Dynamics of plant development and boll accumulation of varieties S-6524 and Sultan in 2018-2019

\begin{tabular}{|c|c|c|c|c|c|c|}
\hline \multirow[b]{3}{*}{$\begin{array}{c}\text { 11,1 meter } \\
\text { sample } \\
\text { areas }\end{array}$} & \multicolumn{3}{|c|}{2018} & \multicolumn{3}{|c|}{2019} \\
\hline & \multirow[b]{2}{*}{$\begin{array}{c}\text { An } \\
\text { average } \\
\text { plant } \\
\text { height, cM } \\
\text { (on } 3^{\text {rd }} \text { of } \\
\text { June) } \\
\end{array}$} & \multicolumn{2}{|c|}{ On $23^{\text {rd }}$ of September } & \multirow[b]{2}{*}{$\begin{array}{c}\text { An average } \\
\text { plant } \\
\text { height, cM } \\
\text { (on } 6^{\text {th }} \text { of } \\
\text { June) }\end{array}$} & \multicolumn{2}{|c|}{ On 22nd of September } \\
\hline & & $\begin{array}{c}\text { Number of } \\
\text { plants, unit } \\
(20.05 . \backslash 23.09 .)\end{array}$ & $\begin{array}{l}\text { Boll numbers } \\
\text { (on } 10 \text { та } \\
\text { plants), unit }\end{array}$ & & $\begin{array}{l}\text { Number of } \\
\text { plants, unit }\end{array}$ & $\begin{array}{c}\text { Boll } \\
\text { numbers } \\
\text { (on } 10 \text { Ta } \\
\text { plants), } \\
\text { unit }\end{array}$ \\
\hline 1 & 6.5 & $100 \backslash 82$ & 27 & 20.8 & 108 & 55 \\
\hline 2 & 13.8 & $57 \backslash 52$ & 33 & 20.5 & 153 & 29 \\
\hline 3 & 18.6 & $106 \backslash 87$ & 39 & 14.5 & 83 & 116 \\
\hline 4 & 7.7 & $60 \backslash 57$ & 117 & 9.1 & 80 & 47 \\
\hline 5 & 11.9 & $142 \backslash 82$ & 16 & 14.9 & 75 & 71 \\
\hline 6 & 7.5 & $37 \backslash 32$ & 74 & 14.0 & 72 & 104 \\
\hline 7 & 14.0 & $65 \backslash 50$ & 19 & 33.0 & 80 & 92 \\
\hline 8 & 19.6 & $71 \backslash 58$ & 69 & 18.5 & 90 & 73 \\
\hline 9 & 11.6 & $94 \backslash 37$ & 37 & 12.0 & 73 & 109 \\
\hline 10 & - & - & - & - & - & - \\
\hline Mean & $12.3+-1.1$ & $82.4 \backslash 59.7$ & 47.9 & 17.5 & 90.4 & 77.3 \\
\hline $\begin{array}{c}\text { Coefficient } \\
\text { of variation, } \\
\%\end{array}$ & 28.2 & & & & & \\
\hline
\end{tabular}

In the data of 2019, development dynamics of plants on the variety Sultan analyzed and compared with the plant dynamics of variety S-6524 from 2018 (table 4). Variety's development in the starting of month June was superior than the development of the variety S6524. Planting of seeds for both varieties had been implemented almost at the one, same time (on $5^{\text {th }}$ and $4^{\text {th }}$ of April). But, comparatively lower temperature and moisture of spring in 2018 [5] caused of inhibition in fully seed germination of seeds of variety S-6524 up to 7 days than seeds of variety Sultan in 2019 (tables 1 and 2). Actually, this substantiates by the weather or hereditarily about 10 days of early maturity of the variety Sultan [10].
This is seen in the table 4, out of difference in the average development of the height of plants at the beginning of June month. At this moment, an average plant height development of the variety S-6524 was $12.3 \mathrm{~cm}$, meantime the plants of the variety Sultan possessed $17.5 \mathrm{~cm}$. Over the field also, the differences of plant height in the samples of this variety have arranged in the order of $33.0 \mathrm{~cm}$ to $9.1 \mathrm{~cm}$. The plants number of this variety was in the samples an average 90.4 unit which is around optimal plant stand over the field. By the way, differences over the samples or field are 72 to 153 . These indexes on the variety of S-6524 correspondingly an average accounted for 59.7 units; from 32 to 87 . Rate of differences over the varieties, 
field, optimal plant stands and variation of number in the plant stand do not meet any requirements.

On the boll number per plants also the variety of Sultan presents a dominant phenomenon (77.3 units) than variety S-6524, which has 47.9 units. The differences in the samples of this variety are extremely great (from 29 up to 116 units), and it has left as the continuation of traits differences on the samples. The number of bolls will define the future yield out of each variety. All above mentioned differences on the bolls and instability in the yield components has begun since seed planting (tables 1 and 2).

The share of influence of variety grade trait on differences of plans development and accumulation of yield components was very mighty. The uniformity (variety trait) of the plants F1 of the variety Sultan was far out in regard the relevant manual [21]. Here, only the analysis of two traits: types of branching and boll shape were enough. 100 plant units in the samples on these two traits have exhibited heterozygous outlook of hybrids than its variety characteristics.

\section{CONCLUSION}

The numbers of seeds planted by the seeder were minimum 9 to maximum 29 in the samples. The result of this index according to the statistical analyze was considerably great, which consisted of $29.7 \%$ on the coefficient of variation.

Field germination has exhibited the indexes accounting for 61 to $100 \%$. An average germination on the samples was equal to $81.2 \%$. Positive correlation between seeds number and germination was not determined. Because of availability of $100 \%$ germinations in both situations: with 20 and with 9 seeds in the samples.

The experiment has demonstrated that there is a good opportunity to promote the best germination and save seed stock through planting 9, 10 seeds of the variety S-6524, evenly per every meter by the help of precision seed drills. On the variety of Sultan, planting of 7 to 9 seeds per meter would be a desirable chance.

Number of seedlings prior to thinning consisted of 103 to 232 per $11.1 \mathrm{~m}$. The difference between these two samples made of 129 sprouts, this shows that this was a prediction about the needless of statistical analyze to identify the importance of difference. The greatness of difference was originated from the actual working quality of seeder which did not meet the requirement.

It clearly was found according to the taken data that more than a half of planting of 16.3 to $37.1 \mathrm{~kg}$ seed stocks per hectare is being lost by the thinning. Thinning does not attract the extra expend, basically its operational quality also in the term of $80-90$ thousand optimal plant stand doesn't the requirement.

Variation associated with positive relation was observed between differences of maintained numbers of plants over the area during the vegetation from May $20^{\text {th }}$ to September $23^{\text {rd }}$. That is losing a lot of plants from enlarged numbers of plants and less from least number of plants.

Natural law about the increasing the fruits number (bolls) depending on the decreasing the number of plant numbers in the field also has been seen. But, the instability of plant numbers in the samples caused of arising considerable differences in the yield component accumulation opportunities of plants.

Above mentioned differences in the studied characteristics of plants existed in the plant heights, optimal plant stands during vegetation and in boll setting properties of plants also.

Beside the low planting quality of employed seeder, the variety impurity of studied varieties, on the example of variety Sultan have the great shares to arising considerable instabilities over all dignities of variety plants in the process of seed production.

According to today's progress, the innovative researches have to be extended in particular for the sake of improving above mentioned two situations in the quality cotton seed stock production in Uzbekistan.

\section{REFERENCES}

1. Resolution, № PQ-3698 of the president of the republic of Uzbekistan: "About additional measurements on the perfection of the innovations introducing mechanisms into industries and economical fields" on May, 2018. (In Uzbek).

2. Ashurov M., Shomukimova A. (2013). Development of cotton field germination and resistance to diseases. $J$. Bulletin of agrarian science of Uzbekistan, № 4, (14). pp.7-10. (In Uzbek).

3. Ashurov M., Ishchanov R., Avezova M. (2006). Search the improved technology on the cotton growing. J. Bulletin of agrarian science of Uzbekistan, № 2, (24). pp.10-14. (In Russian).

4. Ashurov M., Saddinova F., Safaralieva L., Ruzikulov A., Siddikov A. Planting of seed stock in the cotton growing, field germination of seed stock and problems associated with them. J. Bulletin of agrarian science of Uzbekistan, № 2, (72) 2018. p.45-53. (In Uzbek).

5. Ashurov M., Yakubov M., Safaralieva L., Abdumajitov A. Dependence of cotton seed sprouting on temperature. J. Bulletin of agrarian science of Uzbekistan, № 3, (78) 2019. (In Uzbek).

6. Ibrokhimom O. Fruit setting on cotton plant and its managing factors. T., Mekhnat, 1992. (In Uzbek).

7. Kanash S.S. Cotton plant. T. Publishing house of the Academy of Science of Uzbekistan, 1960. (In Russian).

8. Kratirov O.V. (1985). Methodic manual on the seed stock reproduction of oldest generations of cotton varieties included into state register in elite seed stock farms. Tashkent.

9. Nazirov N. (1990). Science and cotton plant. Uzbekistan, 1977. Moscow (In Russian).

10. Tursunov R., Fayzullaev U. (1988). Expense-against mechanism of intensive technology. Selskaya pravda. № 108, from May 13. (In Russian).

11. Nazarov R., Amanturdiev A., Javliev U., Sadikov Kh. (2013). New, perspective and registered cotton varieties, their growing technologies. Tashkent. "Fan", 79 p. (In Uzbek).

12. Khasanov A. Hill planting of cotton in Khavast. (1991). Abstract issues of science-practical conference "Intensification efficiency of agricultural production in the conditions of transition of farms to self - payment and self - finance". December 23-25, pp. 8-9. (In Russian).

13. Khasanov B.O. and others. (2002). Protection of cotton plant from pests, diseases and weeds. Tashkent, 
University publishing house, 381 p. (In Uzbek).

14. Ashurov M., Abdumajitov A., Alimova D., Sadikova M., Mamanazarov M. (2019). Cotton plant importance and cotton production in the countries of the world. J. Bulletin of the agrarian science of Uzbekistan. 1(75). pp. 23-27. (In English).

15. The biology of Gossypium hirsutum L. and Gossypium barbadense L. (cotton). Australian Government. Version 2, February 2008. (In English).

16. Dospekhov B.A. (1985). Field Experimentation. Statistical Procedures., Mir Publishers Moscow, 351 p. (In Russian).

17. UN FoodङAgriculture Organization (2018). http://wwrw.fao.org/faostat/en/\#data/OC.

18. FAO Data. Food and Agriculture Organization, viewed $31^{s} \quad$ January, 2017. http://wwrw.fao.org/faostat/en/\#data/OC.

19. United States Department of Agriculture. Year of estimation: 2018. https://www.usda.gov/.

20. Data of Internet 1. Seeder for sowing cotton. https://www.google.com/search?q=Сеялки + для+noceв $\underline{a+x л о п к а ~(I n ~ R u s s i a n) . ~}$

21. The International Union for the Protection of New Varieties of Plants (UPOV) is an intergovernmental organization with head quarters in Geneva (Switzerland) 1991. (In English). 